\title{
New Potentials of Mixed Reality and its Business Impact Minitrack
}

\author{
Thomas Keller \\ ZHAW \\ kell@zhaw.ch
}

\author{
Roger Seiler \\ ZHAW \\ seir@zhaw.ch
}

The field of extended reality (XR) and XR enabling technology are rapidly advancing. With technology pacing through maturity stages applications in the field are advancing too. These applications range from health, education, construction to human resources management and are drawing attention in the scientific community and the field alike. Furthermore, use cases are being implemented in service and collaboration applications, sales and marketing. This broad range of implementations and applications can in turn create value for and have a broad impact on a company seeking to use mixed reality in a business context. However, many questions on how this technology impacts businesses, customers and if previous theories hold true for this new, much more immersive technology is unclear.

Therefore, this minitrack seeks to gain a deeper understanding of mixed reality and shed light on this new technology as well as its impacts on businesses, customers and to develop new or add to existing theory.
Although this minitrack is not focusing on advancing technical solutions contributions that help businesses use the technology (reference framework or technology navigator) are eligible for consideration and publication in this track too.

For this year two papers were accepted for this minitrack. The paper with the title "Conceptualizing Interactions of Augmented Reality Solutions" focuses on the conceptual understanding of AR interactions and the entire solution space. The authors conceptualize AR solution interactions and provide a comprehensive taxonomy. The second paper with the title "An Efficient Refocusing Scheme for Camera-Array Captured Light Field Video for Improved Visual Immersiveness" deals with a key property of light field. The authors present an approach to improve the visual quality of refocused content captured by a camera array-based setup. 